Available online at_www.iponlinejournal.com

\title{
Efficacy and cost effectiveness comparision between fusidic acid and mupirocin for impetigo
}

\section{Fazeel Zubair Ahmed ${ }^{1 *}$, Anusharani M $\mathbf{~}^{2}$}

${ }^{1}$ Associate Professor, ${ }^{2}$ Tutor,,${ }^{1,2}$ Dept. of Pharmacology, ${ }^{1}$ Viswabharathi Medical College, Kurnool, Andhra Pradesh, ${ }^{2}$ ESI Medical College, Sanathnagar, Hyderabad, India

\begin{abstract}
Introduction: Impetigo is a contagious skin infection due to $S$. aureus or S. pyogenes that usually affects children. BNF recommends topical fusidic acid or mupirocin for impetigo. This study compares the efficacy and cost-effectiveness of topical fusidic acid and mupirocin in treatment of impetigo.

Materials and Methods: This was an open label, prospective study done on 100 impetigo patients attending OPD of Viswabharathi General \& Teaching Hospital, Kurnool, Andhra Pradesh, India from January 2016 to December 2016. The primary end points were evaluated at the baseline, and after one week of treatment. The end points were: number of lesions, size of the lesions, SSI score and cost to treat a single case. Patients were randomly allocated to two groups - fusidic acid group and mupirocin group. In both groups the test drug was applied locally thrice daily. Statistical analysis was done using student's paired t test and unpaired t test. p-value of <0.05 was considered significant.

Results: In fusidic acid group; number of lesions declined from $4.24 \pm 1.17$ to $0.24 \pm 0.82$, wound area $\left(\mathrm{cm}^{2}\right)$ decreased from $3.24 \pm 0.95$ to $0.34 \pm 1.18$ and SSI decreased from $2.32 \pm 0.47$ to $0.14 \pm 0.49$. While in mupirocin group; number of lesions declined from $4.16 \pm 1.11$ to $0.14 \pm 0.70$, wound area $\left(\mathrm{cm}^{2}\right)$ decreased from $3.45 \pm 1.14$ to $0.17 \pm 0.85$ and SSI decreased from $2.44 \pm 0.50$ to $0.08 \pm 0.39$. All these changes were statistically significant. Cost to treat one case was INR 46 for fusidic acid and INR 72 for mupirocin.

Conclusion: Mupirocin is marginally more effective than fusidic acid but this difference was not statistically significant. Cost effectiveness of fusidic acid is less than mupirocin.
\end{abstract}

Keywords: Fusidic acid, Mupirocin, Impetigo, Cost-effectiveness, Efficacy, Comparison.

\section{Introduction}

Impetigo is a highly contagious infection of the superficial epidermis that most often affects children of two to five years age, although it can occur in any age group. It is caused due to infection of $S$. aureus or S. pyogenes. ${ }^{1}$ Among children, impetigo is the most common bacterial skin infection and the third most common skin disease over all, behind dermatitis and viral warts. ${ }^{2,3}$ Recent estimates of the global burden of impetigo are 111 million children from developing countries 140 million people affected at any one time. ${ }^{4,5}$ Impetigo usually is transmitted through direct contact. ${ }^{6}$ Infections often spread rapidly through schools and day care centers. The incidence is greatest in the summer months, and the infection often occurs in areas with poor hygiene and in crowded living conditions .One third of skin and soft tissue infections in returning travelers are attributable to impetigo, usually secondary to infected mosquito bites. ${ }^{7}$ Impetigo is of 2 types - bullous type and non-bullous type.

The highly contagious nature of impetigo also allows spread from patients to close contacts. Although impetigo is considered a self-limited infection, antibiotic treatment is often required for quicker cure, to prevent spread to others and to prevent complications. ${ }^{8,9}$ There is some uncertainty regarding the optimal treatment of impetigo. Advice ranges from the use of oral flucloxacillin, erythromycin, penicillin or cephalosporins to topical treatment with fusidic acid, mupirocin, neomycin or bacitracin. ${ }^{10}$ The British National Formulary (BNF) recommends topical fusidic acid or mupirocin for limited impetigo and oral flucloxacillin or erythromycin for widespread disease. ${ }^{11}$ Topical antibiotics are more effective than placebo and preferable to oral antibiotics for limited impetigo. Topical antibiotic has the advantage of being applied only where needed, thus minimizing antibiotic resistance and avoiding gastrointestinal and other systemic adverse effects. The ideal treatment should be effective, inexpensive, have limited adverse effects, and should not promote bacterial resistance.

This study compares the efficacy and cost-effectiveness of topical fusidic acid and topical mupirocin in treatment of impetigo.

\section{Patients and methods}

This was an open label, prospective study to evaluate efficacy and cost effectiveness of topical $2 \%$ fusidic acid cream with topical $2 \%$ mupirocin ointment in treatment of impetigo. The study was conducted in patients attending OPD of Department of Dermatology at Viswabharathi General \& Teaching Hospital, Kurnool, AP, India. Prior approval was obtained from Institutional Ethics Committee of Viswabharathi medical college and general hospital.

This study was done on 100 patients attending dermatology OPD from January 2016 to December 2016.

*Corresponding Author: Fazeel Zubair Ahmed, Dept. of Pharmacology, Viswabharathi Medical College, Kurnool, Andhra Pradesh, India Email: fazeelzubair@yahoo.com

http://doi.org/10.18231/j.ijcaap.2019.021 


\section{Inclusion criteria}

1. Patients clinically diagnosed as impetigo (bullous and non-bullous).

2. Patients between age group 1-30 years.

3. Patients of either sex.

4. Patients with number of lesions up to 10 (bullous and non-bullous).

\section{Exclusion criteria}

1. Patients with underlying skin diseases such as preexisting eczematous dermatitis or trauma with clinical evidence of secondary infections.

2. Complicated bacterial skin infections such as those requiring the systemic administration of antibiotics, i.e., those associated with lymphadenitis, signs and symptoms of systemic toxicity, extensive skin lesions, and localized deep infections of skin.

3. Patients with HIV infection, diabetes mellitus, or patients on corticosteroids therapy.
4. Patients with known hypersensitivity to fusidic acid and mupirocin.

5. Pregnant women and lactating women.

6. Patients unwilling or unable to comply with the study procedures.

Informed consent was taken from all participating patients. Consent from parents were taken for children below 12 years of age. They were explained about the drugs to be given for their conditions and instructions regarding usage of medications.

The diagnosis of impetigo was confirmed clinically. Scoring system of the lesions was done with reference to parameters like erythema, edema, vesiculation, pustulation and crusting. Scoring was applied to each parameter in the following manner ${ }^{12}$ (Table 1):

Table 1: Scoring system of impetigo (SSI)

\begin{tabular}{|c|l|}
\hline Score & \multicolumn{1}{|c|}{ Comments } \\
\hline 0 & No parameter noticed \\
\hline 1 & Parameter noticed by the patient and the physician, not disturbing the patient \\
\hline 2 & Parameter definitely present and interfering with some activity and sleep \\
\hline 3 & Parameter marked and disturbing and interfering with some activity and sleep. \\
\hline
\end{tabular}

Table 2: Demographic distribution of the patients in groups I \& II

\begin{tabular}{|c|c|c|c|c|}
\hline & Group I (Fusidic Acid) & Group II (Mupirocin) \\
\hline & n & \% & n & \% \\
\hline \multicolumn{5}{|c|}{ Gender } \\
\hline Male & 29 & 58 & 31 & 62 \\
\hline Female & 21 & 42 & 19 & 38 \\
\hline \multicolumn{5}{|c|}{ Age } \\
\hline 01 to 10 yrs & 29 & 58 & 33 & 66 \\
\hline 11 to 20 yrs & 13 & 26 & 11 & 22 \\
\hline 21 to 30 yrs & 8 & 16 & 6 & 12 \\
\hline \multicolumn{7}{|c|}{ Type of Lesion } \\
\hline Non - bullous & 39 & 78 & 37 & 74 \\
\hline Bullous & 11 & 22 & 13 & 26 \\
\hline
\end{tabular}

Table 3: Baseline characteristics of two treatment groups

\begin{tabular}{|c|c|c|c|}
\hline Parameters & $\begin{array}{c}\text { Group I } \\
\text { (Fusidic Acid) }(\mathbf{n}=\mathbf{5 0})\end{array}$ & $\begin{array}{c}\text { Group II (Mupirocin) } \\
(\mathbf{n}=\mathbf{5 0})\end{array}$ & \\
\hline Age in years $($ Mean \pm SD) & $10.46 \pm 7.61$ & $9.6 \pm 7.18$ & $\mathrm{p}$-value $>0.05$ \\
\hline Gender ratio (Male\% / Female\%) & $58 / 42$ & $62 / 38$ & \\
\hline Scoring System of Impetigo & $2.32 \pm 0.47$ & $2.44 \pm 0.50$ & p-value $>0.05$ \\
\hline No. of Lesions (Mean \pm SD) & $4.24 \pm 1.17$ & $4.16 \pm 1.11$ & p-value $>0.05$ \\
\hline Size of Lesions $\left(\mathrm{cm}^{2}\right)($ Mean \pm SD $)$ & $3.24 \pm 0.95$ & $3.45 \pm 1.14$ & $\mathrm{p}$-value $>0.05$ \\
\hline
\end{tabular}

Table 4: Clinical Cure for Fusidic acid

\begin{tabular}{|c|l|c|c|c|}
\hline S. No & Parameter & Before Treatment & After Treatment & p-value \\
\hline 1 & No. of Lesions (Mean \pm SD) & $4.24 \pm 1.17$ & $0.24 \pm 0.82$ & $<0.05^{*}$ \\
\hline 2 & Wound Area $\left(\mathrm{cm}^{2}\right)($ Mean \pm SD) & $3.24 \pm 0.95$ & $0.34 \pm 1.18$ & $<0.05^{*}$ \\
\hline 3 & SSI (Mean \pm SD) & $2.32 \pm 0.47$ & $0.14 \pm 0.49$ & $<0.05^{*}$ \\
\hline
\end{tabular}


Table 5: Clinical cure for mupirocin

\begin{tabular}{|c|l|c|c|c|}
\hline S. No & \multicolumn{1}{|c|}{ Parameter } & Before Treatment & After Treatment & p-value \\
\hline 1 & No. of Lesions $($ Mean \pm SD) & $4.16 \pm 1.11$ & $0.14 \pm 0.70$ & $<0.05^{*}$ \\
\hline 2 & Wound Area $\left(\mathrm{cm}^{2}\right)($ Mean \pm SD) & $3.45 \pm 1.14$ & $0.17 \pm 0.85$ & $<0.05^{*}$ \\
\hline 3 & SSI (Mean \pm SD) & $2.44 \pm 0.50$ & $0.08 \pm 0.39$ & $<0.05^{*}$ \\
\hline${ }^{*}$ statistically significant
\end{tabular}

Table 6: Clinical Outcome in two treatment groups at the end of first week

\begin{tabular}{|l|c|c|c|}
\hline \multicolumn{1}{|c|}{ No. of Patients } & Group I & Group II & p-value \\
\cline { 1 - 3 } Cured (SSI = 0 and Absence of lesions) & 46 & 48 & \\
\cline { 1 - 3 } Not Cured (SSI = 1 - 2 and presence of lesions) & 4 & 2 & \multirow{2}{*}{$>0.05$} \\
\hline Efficacy & $92 \%$ & $96 \%$ & \\
\hline
\end{tabular}

Table 7: Comparison of clinical cure for Group I \& II after one week of treatment

\begin{tabular}{|c|l|c|c|c|}
\hline S. No & \multicolumn{1}{|c|}{ Parameter } & Group I (Fusidic Acid) & Group II (Mupirocin) & p-value \\
\hline 1 & No. of Lesions $($ Mean \pm SD) & $0.24 \pm 0.82$ & $0.14 \pm 0.70$ & $>0.05$ \\
\hline 2 & Wound Area $\left(\mathrm{cm}^{2}\right)($ Mean \pm SD) & $0.34 \pm 1.18$ & $0.17 \pm 0.85$ & $>0.05$ \\
\hline 3 & SSI $($ Mean \pm SD) & $0.14 \pm 0.49$ & $0.08 \pm 0.39$ & $>0.05$ \\
\hline
\end{tabular}

Table 8: Adverse events in study groups

\begin{tabular}{|l|c|c|c|c|}
\hline & \multicolumn{2}{|c|}{ Group I (Fusidic Acid) } & \multicolumn{2}{c|}{ Group II (Mupirocin) } \\
\cline { 2 - 5 } & $\mathbf{n}$ & $\boldsymbol{\%}$ & $\mathbf{n}$ & $\boldsymbol{\%}$ \\
\hline Irritation at the site of application & 3 & $6 \%$ & 3 & $6 \%$ \\
\hline
\end{tabular}

Table 9: Cost effectiveness of each study drug at the end of first week based on overall cure rate

\begin{tabular}{|l|c|c|}
\hline \multicolumn{1}{|c|}{ Parameters } & Fusidic Acid & Mupirocin \\
\hline Cost in INR for 100 participants & $42 \times 100=4200$ & $69 \times 100=6900$ \\
\hline Overall Cure rate (\%) & 92 & 96 \\
\hline Cost effectiveness & 4200 for 92 participants & 6900 for 96 participants \\
\hline Cost in INR to treat one case & 46 & 72 \\
\hline
\end{tabular}

Apart from the above parameters, wound areas was also taken as a parameter. Wound area was measured by the greatest length of the wound in two perpendicular dimensions with a standard metric ruler. The two measurements were multiplied together to obtain the overall wound size.

The primary end points were evaluated two times in the study, at the baseline, and after one week of treatment.

These end points included:

1. Clinical cure assessed by scoring system of impetigo. ${ }^{12}$

2. Clinical cure defined as the number of lesions before and after treatment. ${ }^{13}$

3. Clinical cure defined as the approximate size of the lesions before and after treatment. ${ }^{14}$

4. Cost effectiveness as cost in INR to treat a single case successfully.

Patients were randomly allocated to two treatment groups fusidic acid group and mupirocin group. In both groups the test drug was applied locally three times a day.

\section{Efficacy assessment}

The patients of the two groups were followed up at the end of first week to assess the efficacy. ${ }^{15}$ At the end of first week a detailed clinical examination was performed. SSI assessed, number of lesions and size of existing lesions were measured. The clinical outcome was graded as Mild to Moderate (SSI score 1 or 2 and presence of lesions), Good (SSI score 0 and no lesions).

The treatment was considered effective only if at the end of first week the SSI score 0, no. of lesions 0 , size of lesions 0 and the lesions were totally improved without appearance of any new lesions from initial visit. ${ }^{14,16,17}$ The patients were asked for any adverse events occurred during the course of treatment.

\section{Cost effectiveness assessment}

The cost effectiveness was calculated on the basis of total expenditure on medicine in INR at the end of first week, cure rate and the two drugs were compared on the basis of amount needed to treat one case successfully. ${ }^{15}$

\section{Statistical analysis}

The Statistical analysis was carried out using SPSS. All the data was presented as Mean \pm SD. Student's paired t-test was used to evaluate efficacy of a drug and student's unpaired ttest was used to evaluate the statistical significance between the two drugs. p-value of $<0.05$ was considered significant. 


\section{Observations and Results}

Of the 100 patients enrolled in study, 60 were males and 40 were females. 62 patients were of age $<10$ years, 24 were of age $11-20$ years and 14 were of $21-30$ years of age. 76 cases had non bullous lesions and 24 had bullous lesions (Table 2). Before starting the treatment, both groups had almost number of lesions, size of lesions and SSI (Table 3).

In group I - fusidic acid group; number of lesions declined from $4.24 \pm 1.17$ to $0.24 \pm 0.82$, wound area $\left(\mathrm{cm}^{2}\right)$ decreased from $3.24 \pm 0.95$ to $0.34 \pm 1.18$ and SSI decreased from $2.32 \pm 0.47$ to $0.14 \pm 0.49$. All these changes were statistically significant when compared before and after treatment with $\mathrm{p}<0.05$ (Table 4). While in group II mupirocin group; number of lesions declined from $4.16 \pm 1.11$ to $0.14 \pm 0.70$, wound area $\left(\mathrm{cm}^{2}\right)$ decreased from $3.45 \pm 1.14$ to $0.17 \pm 0.85$ and SSI decreased from $2.44 \pm 0.50$ to $0.08 \pm 0.39$. All these changes were statistically significant when compared before and after treatment with $\mathrm{p}<0.05$ (Table 5).

Inter group comparison between these two groups after treatment was similar and not statistically significant (Table 6). Clinical efficacy in group I - fusidic acid group was seen in 46 cases out of 50 while that in group II - mupirocin group was seen in 48 cases out of 50 (Table 7).

Only mild adverse events were noted in both groups and they did not require any specific treatment. Irritation at the site of application was observed in three patients in group I and in three patients of group II (Table 8).

Cost of one tube of fusidic acid was INR 42.00 and that of mupirocin was INR 69. Overall cure rate in fusidic acid was $92 \%$ and that in mupirocin was $96 \%$. Hence cost to treat one case was INR 46 for fusidic acid and INR 72 for mupirocin (Table 9).

\section{Discussion}

Impetigo is a common, highly contagious superficial bacterial skin infection caused by either Staphylococcus aureus or streptococcus or both. Staphylococcus is the most common agent in temperate climates, whereas streptococcal impetigo is more often seen in hot, humid areas. All ages can contract the infection but non-bullous disease particularly affects young children, often in late summer. ${ }^{18,19}$ It can be sporadic, although outbreaks can arise in conditions of overcrowding and poor hygiene or in institutions. A widespread form can occur in neonates. Predisposing factors are minor skin abrasions and the existence of other skin conditions, such as infestations or eczema. $^{20}$ The diagnosis of non-bullous and bullous impetigo is nearly always clinical. Treatment options for impetigo include topical antibiotics, systemic antibiotics and topical disinfectants depending on the severity. ${ }^{21}$ Among the topical antibiotics, fusidic acid and mupirocin are quite commonly used. ${ }^{22}$

In group I (Fusidic acid) the clinical cure parameters were assessed before and after treatment for one week. The number of lesions before treatment were $4.24 \pm 1.17$ and after one week of treatment was $0.24 \pm 0.82$ with $\mathrm{p}$-value $<0.05$ which was statistically significant. The wound area $\left(\mathrm{cm}^{2}\right)$ before treatment was $3.24 \pm 0.95$ and after one week of treatment was $0.34 \pm 1.18$ with $\mathrm{p}$-value $<0.05$ which was statistically significant. The SSI before treatment was $2.32 \pm 0.47$ and after one week of treatment was $0.14 \pm 0.49$ with p-value $<0.05$ which was statistically significant. While in group II (Mupirocin), the number of lesions before treatment were $4.16 \pm 1.11$ and after one week of treatment was $0.14 \pm 0.70$ with $\mathrm{p}$-value $<0.05$ which was statistically significant. The wound area $\left(\mathrm{cm}^{2}\right)$ before treatment was $3.45 \pm 1.14$ and after one week of treatment was $0.17 \pm 0.85$ with p-value $<0.05$ which was statistically significant. The SSI before treatment was $2.44 \pm 0.50$ and after one week of treatment was $0.08 \pm 0.39$ with p-value $<0.05$ which was statistically significant. The p-value was calculated using student's paired t-test.

Clinical efficacy was defined as no lesions and SSI score zero after one week of treatment along with no appearance of any new lesions from initial visit. Percentage of patients cured to the total number of patients in the study group was taken as clinical efficacy. The efficacy of group I (Fusidic acid) was 92\% while that of group II (Mupirocin) $96 \%$. Clinical outcome after one week in both groups was similar and not statistically significant. Student's unpaired t test was used to calculate $\mathrm{p}$ value.

Adverse effects reported in this study were mild and did not require any specific treatment or discontinuation of drug. 3 cases in each group complained of skin irritation at site of application.

Cost effectiveness of each study drug at the end of first week based on overall cure rate was calculated in INR (Indian National Rupee). The cost incurred to treat one case successfully was INR 46 for fusidic acid and INR 72 for mupirocin. So fusidic acid was more cost effective than mupirocin in treatment of impetigo.

Results of our study with regard to clinical effectiveness are consistent with study done by Koning et al. They found no difference between effectiveness of mupirocin and fusidic acid. ${ }^{23}$ Chosidow et. al. compared retapamulin with fusidic acid and found that adverse effects were virtually nonexistent with fusidic acid. ${ }^{24}$ In our study too only $6 \%$ cases in fusidic acid group complained of mild adverse effect. We could not find any study that compared cost effectiveness of mupirocin and fusidic acid.

In our study proper randomization was used to allocate a patient to a treatment group. Care was taken to maintain similar demographics in both groups. 50 cases were assigned to each group keeping in view the accepted sample size. Cost effectiveness was also compared in this study which was not done in any previous studies.

However, our study was limited to mild - moderate cases of impetigo having $\leq 10$ lesions. Impetigo with secondary bacterial infections were excluded here and the outcome may vary in such cases. Further studies are required in various subsets of impetigo cases. 


\section{Conclusion}

Clinical efficacy of fusidic acid was $92 \%$ and of mupirocin was $96 \%$. Similar adverse events were reported in both groups. Hence mupirocin is marginally more effective than fusidic acid but this difference is not statistically significant. Cost incurred to treat one case successfully with fusidic acid was INR 46 and that for mupirocin was INR 72. Cost effectiveness of fusidic acid is less than mupirocin.

\section{Source of Funding}

None.

\section{Conflicts of Interest}

None.

\section{References}

1. Koning S, VD Sande R, Verhagen AP, Van Suijlekom-Smit $\mathrm{LW}$, Morris AD, Butler CC, et al. Interventions for impetigo. Cochrane Skin Group, editor. Cochrane Database Syst Rev 2012 Jan 18 [cited 2019 Jul 9]; Available from: http://doi.wiley.com/10.1002/14651858.CD003261.pub3

2. Sladden MJ, Johnston GA. Common skin infections in children. BMJ 2004;329(7457):95-9.

3. Brown J, Shriner DL, Schwartz RA, Janniger CK. Impetigo: an update. Int J Dermatol 2003;42(4):251-5.

4. Vos T, Flaxman AD, Naghavi M, Lozano R, Michaud C, Ezzati M, et al. Years lived with disability (YLDs) for 1160 sequelae of 289 diseases and injuries 1990-2010: a systematic analysis for the Global Burden of Disease Study 2010. Lancet 2012;380(9859):2163-96.

5. Hay RJ, Johns NE, Williams HC, Bolliger IW, Dellavalle RP, Margolis DJ, et al. The Global Burden of Skin Disease in 2010: An Analysis of the Prevalence and Impact of Skin Conditions. J Invest Dermatol 2014;134(6):1527-34.

6. Cole C, Gazewood J. Diagnosis and treatment of impetigo. Am Fam Physician 2007;75(6):859-64.

7. Hochedez P, Canestri A, Lecso M, Valin N, Bricaire F, Caumes E et al.. Skin and soft tissue infections in returning travelers. Am J Trop Med Hyg 2009;80(3):431-4.

8. Feaster T, Singer JI. Topical therapies for impetigo. Pediatr Emerg Care 2010;26(3):222-7; quiz 228-31.

9. Weinberg JM, Tyring SK. Retapamulin: an antibacterial with a novel mode of action in an age of emerging resistance to Staphylococcus aureus. J Drugs Dermatol 2010;9(10):1198204.

10. Hay RJ, Adriaans BM. Bacterial infections. In: Champion RH, Rook A, Wilkinson DS, Ebling FJG, Rook A, editors. Rook/Wilkinson/Ebling textbook of dermatology. 6th ed. Oxford; Malden, MA: Blackwell Science; 1998.

11. Joint Formulary Committee. Antibacterial drugs. In: British National Formulary (BNF). London: Pharmaceutical Press; 2014.
12. Resham J Vasani, Sudhir V Medhekar. Topical $2 \%$ mupirocin versus $2 \%$ fusidic acid versus $1 \%$ nadifloxacin cream in the treatment of superficial bacterial infections of the skin. 5 Indian J Drugs Dermatol 2015;1(1):16-8.

13. Koranyi KI, Burech DL, Haynes RE. Evaluation of bacitracin ointment in the treatment of impetigo. Ohio State Med $\mathrm{J}$ 1976;72(6):368-70.

14. Motswaledi M. Impetigo in children: a clinical guide and treatment options. South Afr Family Pract 2011;53(1):44-6.

15. George A, Rubin G. A systematic review and meta-analysis of treatments for impetigo. Br J Gen Pract 2003;53(491):480-7.

16. Jeffrey LT, Britton W, Fajardo JE, Krafte-Jacobs B. Comparison of mupirocin and erythromycin in the treatment of impetigo. J Pediatr 1990;117(5):827-9.

17. Demidovich CW, Wittler RR, Ruff ME, Bass JW, Browning WC. Impetigo. Current etiology and comparison of penicillin, erythromycin, and cephalexin therapies. Am J Dis Child 1990;144(12):1313-5.

18. Gupta V. Clinicoepidemiological study of vesiculobullous disorders in pediatric age group. Indian J Paediatr Dermatol 2015;16(1):9.

19. Awal G, Kaur T. A clinico-bacteriological study of pyodermas in pediatric population. Int J Res Dermatol 2018;4(1):29.

20. Innes JA, Maxwell SRJ, Skin disease. In: Davidson's essentials of medicine. Second edition. Edinburgh ; New York: Elsevier; 2016;687-729.

21. Lawley LP, McCall CO, Lawley TJ. Eczema, Psoriasis, Cutaneous Infections, Acne, and Other Common Skin Disorders. In: Kasper DL, editor. Harrison's Princ Int Med 19th edition / editors, Dennis L. Kasper, MD, William Ellery Channing, Professor of Medicine, Professor of Microbiology, Department of Microbiology and Immunobiology, Harvard Medical School, Division of Infectious Diseases, Brigham and Women's Hospital, Boston, Massachusetts [and five others]. New York: McGraw Hill Education; 2015. p. 334-52.

22. Matthew J. Sewell, Craig N. Burkhart, Dean S. Morrell. Dermatological Pharmacology. In: Brunton LL, Knollmann BC, Hilal-Dandan R, editors. Goodman \& Gilman's the pharmacological basis of therapeutics. Thirteenth edition. New York: McGraw Hill Medical; 2018;1271-96.

23. Koning S. Fusidic acid cream in the treatment of impetigo in general practice: double blind randomised placebo controlled trial. BMJ 2002;324(7331):203.

24. Oranje AP, Chosidow O, Sacchidanand S, Todd G, Singh K, Scangarella N, et al. Topical Retapamulin Ointment, 1\%, versus Sodium Fusidate Ointment, 2\%, for Impetigo: A Randomized, Observer-Blinded, Noninferiority Study. Dermatol 2007;215(4):331-40.

How to cite this article: Ahmed FZ, Anusharani MV. Efficacy and cost effectiveness comparision between fusidic acid and mupirocin for impetigo. Int $J$ Comprehensive $A d v$ Pharmacol 2019;4(3):100-4. 